\title{
Depression of central respiratory drive by nitrazepam
}

\author{
MICHAEL RUDOLF, D. M. GEDDES, J. A. McM. TURNER, AND K. B. SAUNDERS \\ From the Department of Medicine, The Middlesex Hospital, London, UK
}

Rudolf, M., Geddes, D. M., Turner, J. A. McM., and Saunders, K. B. (1978). Thorax, 33, 97-100. Depression of central respiratory drive by nitrazepam. In a group of patients with chronic bronchitis, repeated night sedation with $10 \mathrm{mg}$ nitrazepam produced a fall in central respiratory drive and a steady rise in arterial carbon dioxide tension. The changes produced over a five-day period were not clinically important, except in two patients who were already hypercapnic before receiving nitrazepam. The use of this drug in patients with carbon dioxide retention should be avoided.

Nitrazepam (Mogadon), a benodiazepine, is now regarded as the hypnotic of choice in this country (British Medical Journal, 1976). There have been several case reports of the apparent precipitation by nitrazepam of respiratory failure in patients with pre-existing pulmonary disease (Clark et al., 1971; Hilton, 1971; Pines, 1972; Model, 1973), but the mechanism of this respiratory depression is unclear (Gaddie et al., 1972).

We have shown that a single 5-mg dose of nitrazepam fails to produce any significant depression of central respiratory drive (as assessed by the ventilatory response to carbon dioxide) either in subjects without lung disease or in patients with chronic bronchitis (Geddes et al., 1976). Since repeated administration of nitrazepam at 24-hour intervals is known to produce a steady rise in plasma levels of the drug over the first four to five days (Reider and Wendt, 1973), cumulative effects might be anticipated. We have, therefore, studied the effect of repetated doses of nitrazepam on respiratory drive in a group of patients with chronic bronchitis over a period of five days.

\section{Patients and methods}

\section{PATIENTS}

Twelve patients ( 8 male, 4 female, age range 46-76) were studied. All had smoked more than 20 cigarettes a day for more than 15 years, had chronic bronchitis as defined by the Medical Research Council (1965) with spirometric evidence of fixed airway obstruction, and were in a clinically stable state. Three of the subjects had chronic hypercapnia.

Informed consent was obtained from every patient, and the study was approved by the hospital's ethical committee.

\section{METHODS}

Central respiratory drive was assessed by measuring the increase in ventilation produced by progressive hypercapnia, using the rebreathing technique of Read (1967). Ventilation was measured by integrating the flow signal from a pneumotachograph, and $\mathrm{PCO}_{2}$ was continuously monitored with a Beckman infra-red $\mathrm{CO}_{2}$ analyser. The resulting ventilatory response to $\mathrm{CO}_{2}$ was expressed as the slope of the line obtained by performing least squares regression analysis of the minute ventilation on end-tidal $\mathrm{PCO}_{2}$, ignoring the first 30 seconds of rebreathing. The theoretical intercept of the slope at 'zero' ventilation was also calculated.

Arterial blood samples were obtained when the patients were at rest breathing room air, and the arterial oxygen and carbon dioxide tensions $\left(\mathrm{PaO}_{2}\right.$ and $\mathrm{PaCO}_{2}$ ) and $\mathrm{pH}$ were measured on standard Radiometer electrodes. All measurements were performed in duplicate, and the electrodes were calibrated immediately before and after each sample with standard gases and buffers.

Forced expired volume in one second $\left(\mathrm{FEV}_{1}\right)$ was measured on a Vitalograph spirometer, and the best of three attempts was recorded.

PROTOCOL

All patients had previously performed the $\mathrm{CO}_{2}$ rebreathing test on at least one occasion in order to familiarise themselves with the procedure. Arterial blood gases, spirometry, and ventilatory response to $\mathrm{CO}_{2}$ were measured, and nitrazepam, $10 \mathrm{mg}$, was 
then given at 2200 hours for the next five nights, with repeat measurements, always at the same time of day, made on the first, third, and fifth days. No change in any concurrent drug therapy was made throughout the trial and no other sedatives or hypnotics were given.

Differences between the values obtained on the different days were analysed for statistical significance using Student's $t$ test for paired data.

\section{Results}

\section{ARTERIAL BLOOD GASES}

The daily carbon dioxide tensions in all patients are shown in the Figure. In two of the patients treat-

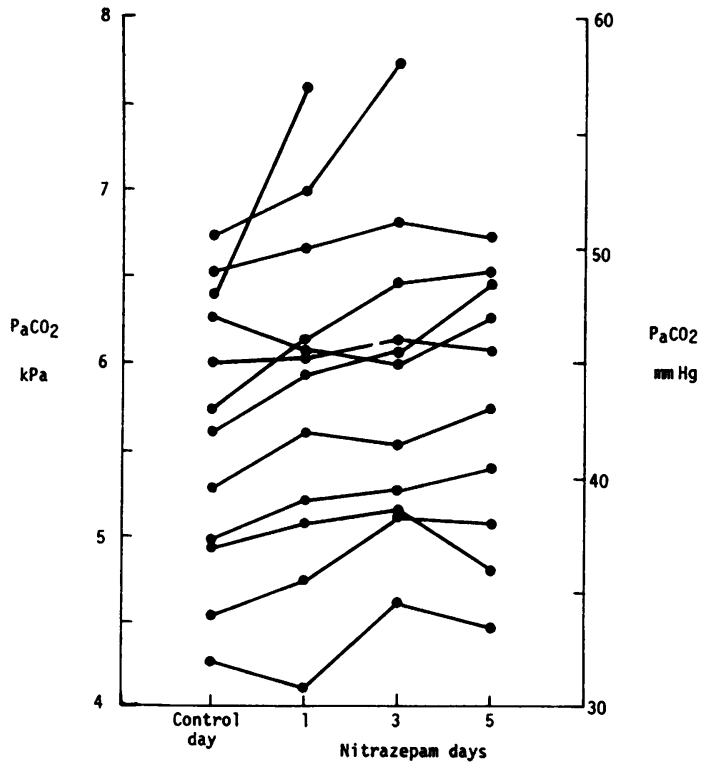

Figure Daily arterial carbon dioxide tensions in all 12 patients. ment had to be discontinued because $\mathrm{PaCO}_{2}$ rose by $1 \mathrm{kPa}(7.5 \mathrm{mmHg})$ or more; both of these patients had been hypercapnic before receiving nitrazepam. Eight $\frac{\bar{\sigma}}{\bar{N}}$ of the remaining 10 patients had an increase in $\mathbb{\nabla}$ $\mathrm{PaCO}_{2}$ at the end of their five days' treatment, and 2 there was a steady rise in mean $\mathrm{PaCO}_{2}$ over the five os days, as shown in the Table. (The results in the two $\vec{O}$ subjects who were withdrawn from the study are not included in these mean values.) The mean $\mathrm{PaCO}_{2} \underset{\mathrm{O}}{\mathrm{S}}$ on every day of nitrazepam treatment was significantly greater than the control value $(P<0.05$ for $x$ day $1, \mathrm{P}<0.01$ for days 3 and 5), and the mean levels $\underset{\omega}{\omega}$ on days 3 and 5 were also significantly higher than on day $1(\mathrm{P}<0.05)$.

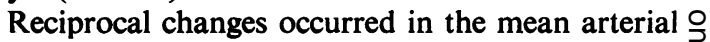
$\mathrm{pH}$ levels. There were no significant changes in mean $\mathrm{PaO}_{2}$, and clinically important hypoxaemia was not T precipitated in any patient.

\section{SPIROMETRY}

There were no significant changes in spirometry, and $\overrightarrow{0}$ FEV $_{1}$ remained unchanged in the two patients who $\infty$ developed severe hypercapnia.

\section{VENTILATORY RESPONSES TO CARBON DIOXIDE}

$\mathrm{CO}_{2}$ response fell by one-third in both of the patients who had to be withdrawn from the study. The mean $\stackrel{\circ}{\Phi}$ response for the remaining 10 patients fell steadily over the five days (Table) and was significantly lower at the end of the study $(P<0.05)$. All eight subjects whose $\mathrm{PaCO}_{2}$ had risen showed a decrease in ventilatory response. No significant differences between the intercepts at zero ventilation were found.

\section{Discussion}

Although some benzodiazepines have been shown to cause respiratory depression in both animals and humans (Flórez, 1971; Gasser and Bellville, 1976;

Table Mean values $( \pm S D)$ of blood gases, spirometry, and ventilatory response to $\mathrm{CO}_{2}$ for the 10 patients who completed the study

\begin{tabular}{|c|c|c|c|c|}
\hline \multirow[b]{3}{*}{$\begin{array}{l}\mathrm{PaCO}_{2}(\mathrm{kPa}) \\
\mathrm{PaO}_{2}(\mathrm{kPa}) \\
\text { pH } \\
\text { FEV } \\
\text { Ventilatore }) \\
\text { to } \mathrm{CO}_{2}\left(\mathrm{~min}^{-1} \mathrm{kPa}^{-1}\right)\end{array}$} & \multirow[b]{2}{*}{ Control } & \multicolumn{3}{|l|}{ Nitrazepam } \\
\hline & & Day 1 & Day 3 & Day 5 \\
\hline & $\begin{array}{l}5.4( \pm 0.7) \\
8.8( \pm 1 \cdot 6) \\
7.41( \pm 0 \cdot 02) \\
1.45( \pm 0.82) \\
7.53( \pm 3.52)\end{array}$ & $\begin{array}{l}5 \cdot 6( \pm 0 \cdot 8)^{*} \\
8 \cdot 7( \pm 1 \cdot 7) \\
7 \cdot 38( \pm 0 \cdot 02)^{*} \\
1 \cdot 45( \pm 0 \cdot 83) \\
6 \cdot 79( \pm 2 \cdot 40)\end{array}$ & $\begin{array}{l}5 \cdot 7( \pm 0 \cdot 7) \pm \S \\
8 \cdot 5( \pm 1 \cdot 5) \\
7 \cdot 37( \pm 0 \cdot 02) \dagger \S \\
1 \cdot 47( \pm 0 \cdot 88) \\
6 \cdot 29( \pm 3 \cdot 75)\end{array}$ & $\begin{array}{l}5 \cdot 8( \pm 0 \cdot 8) \ddagger \S \\
8 \cdot 5( \pm 1 \cdot 3) \\
7 \cdot 36( \pm 0 \cdot 03) \dagger \S \\
1 \cdot 50( \pm 0 \cdot 87) \\
5 \cdot 90( \pm 2 \cdot 65)^{*}\end{array}$ \\
\hline \multicolumn{5}{|c|}{$\begin{array}{l}\text { *Significantly different from control }(\mathrm{P}<0.05) \\
\text { +Significantly different from control }(\mathrm{P}<0.02) \\
\text { tSignificantly different from control }(\mathrm{P}<0.01) \\
\text { \$Significantly different from level on day } 1(\mathrm{P}<0.05) \\
\text { There were no significant changes in } \mathrm{PaO}_{2} \text { or } \mathrm{FEV} \\
\text { Conversion factor: } 1 \mathrm{kPa}=7.5 \mathrm{mmHg}\end{array}$} \\
\hline
\end{tabular}


Geddes et al., 1976), the only previous evidence that nitrazepam might decrease the central drive to breathing is that, when given intravenously to decerebrate cats, it raises arterial $\mathrm{PCO}_{2}$ and depresses the ventilatory response to carbon dioxide (Flórez, 1971). The results of the present study show that nitrazepam does indeed depress the central respiratory drive in man.

Measurement of the ventilatory response to $\mathrm{CO}_{2}$ is a rapid and easily performed method of assessing the effects of drugs on the respiratory control system and, as long as lung mechanics remain constant, any change in this response represents a change in central drive. Opiates, barbiturates, and other benzodiazepines have been shown to depress central respiratory drive using this technique (Gasser et al., 1975; Weil et al., 1975; Gasser and Bellville, 1976; Geddes et al., 1976). The steady decrease in mean $\mathrm{CO}_{2}$ response over the five days of the study suggests that nitrazepam-induced suppression of ventilatory drive is a cumulative effect. However, whereas this fall in $\mathrm{CO}_{2}$ sensitivity did not attain statistical significance until the fifth day, the increase in mean $\mathrm{PaCO}_{2}$ was statistically significant by day 1 . Although this can be explained by the greater variance of the former measurement, it does raise the possibility that something other than depression of respiratory drive might have been causing these changes in $\mathrm{PaCO}_{2}$.

Two possible explanations are (1) that $\mathrm{PaCO}_{2}$ may have risen as a result of increasing maldistribution of ventilation:perfusion ratios throughout the lung (West, 1963), and there is some evidence that diazepam, another benzodiazepine, can cause this (Catchlove and Kafer, 1971a, 1971b), and (2) that the respiratory depression may have been produced, not by an effect on central drive, but by the known ability of benzodiazepine drugs to cause muscle relaxation and consequent impairment of ventilatory capacity (Gaddie et al., 1972; Model and Berry, 1974). The absence of any significant changes in either $\mathrm{PaO}_{2}$ or $\mathrm{FEV}_{1}$ in our study argues against both these possibilities, and we believe that the increase in $\mathrm{PaCO}_{2}$ that we observed was most likely due to the decrease in central drive rather than to any other cause.

Although sedatives and hypnotics are generally considered always to be contraindicated in patients with acute respiratory failure, their position in the treatment of patients with chronic stable respiratory failure is less certain. It is often tempting to use such drugs, especially when nocturnal dyspnoea and insomnia are problems, and, in the absence of any previously proven respiratory depressant effect, nitrazepam has been assumed to be comparatively safe in these circumstances. We feel that the results of this study make this assumption no longer justified, and that the presence of chronic hypercapnia should make one strongly resist the temptation to prescribe nitrazepam or any other hypnotic.

The chronic bronchitics with normal arterial $\mathrm{PCO}_{2}$ showed blood gas changes which, although statistically significant, were small and of little clinical relevance. Nevertheless it would seem sensible to exercise caution in prescribing nitrazepam to these patients since the drug-induced depression of central respiratory drive might well become of critical importance when acute exacerbations of the disease occur.

During this work Dr. Rudolf and Dr. Turner held Sir Jules Thorn Research Fellowships.

\section{References}

British Medical Journal (1976). Glutethimide-an unsafe alternative to barbiturate hypnotics (leading article). British Medical Journal, 1, 1424-1425.

Catchlove, R. F. H., and Kafer, E. R. (1971a). The effects of diazepam on the ventilatory response to carbon dioxide and on steady-state gas exchange. Anesthesiology, 34, 9-13.

Catchlove, R. F. H., and Kafer, E. R. (1971b). The effects of diazepam on respiration in patients with obstructive pulmonary disease. Anesthesiology, 34, 14-18.

Clark, T. J. H., Collins, J. V., and Tong, D. (1971). Respiratory depression caused by nitrazepam in patients with respiratory failure. Lancet, 2, 737-738.

Flórez, J. (1971). The action of diazepam, nitrazepam, and clonazepam on the respiratory centre of decerebrate cats. European Journal of Pharmacology, 14, 250-256.

Gaddie, J., Legge, J. S., Palmer, K. N. V., Petrie, J. C., and Wood, R. A. (1972). Effect of nitrazepam in chronic obstructive bronchitis. British Medical Journal, 2, 688-689.

Gasser, J. C., and Bellville, J. W. (1976). The respiratory effects of hydroxyzine, diazepam, and pentazocine in man. Anaesthesia, 31, 718-723.

Gasser, J. C., Kaufman, R. D., and Bellville, J. W. (1975). Respiratory effects of lorazepam, pentobarbital, and pentazocine. Clinical Pharmacology and Therapeutics, 18, $170-174$.

Geddes, D. M., Rudolf, M., and Saunders, K. B. (1976). Effect of nitrazepam and flurazepam on the ventilatory response to carbon dioxide. Thorax, 31, 548-551.

Hilton, A. M. (1971). Sedative drugs in respiratory failure. Lancet, 2, 922.

Medical Research Council (1965). Definition and classification of chronic bronchitis for clinical and epidemiological purposes. Lancet, 1, 775-779.

Model, D. G. (1973). Nitrazepam induced respiratory depression in chronic obstructive lung disease. British Journal of Diseases of the Chest, 67, 128-130.

Model, D. G., and Berry, D. J. (1974). Effects of chlordiazepoxide in respiratory failure due to chronic bronchitis. Lancet, 2, 869-870. 
Pines, A. (1972). Nitrazepam in chronic obstructive bronchitis. British Medical Journal, 3, 352.

Read, D. J. C. (1967). A clinical method for assessing the ventilatory response to carbon dioxide. Australasian Annals of Medicine, 16, 20-32.

Reider, J., and Wendt, G. (1973). Pharmacokinetics and metabolism of the hypnotic nitrazepam. In The Benzodiazepines, edited by S. Garattini, E. Mussini, and L. O. Randall, p. 99. Raven Press, New York.

Weil, J. V., McCullough, R. E., Kline, J. S., and Sodal,
I. E. (1975). Diminished ventilatory response to hypoxia and hypercapnia after morphine in normal man. New England Journal of Medicine, 292, 1103-1106.

West, J. B. (1963). Blood-flow, ventilation and gas exchange in the lung. Lancet, 2, 1055-1058.

Requests for reprints to: Dr. M. Rudolf, Department of Medicine, The Middlesex Hospital, Mortimer Street, London, W1N 8AA. 